Anca ȘERBAN

Oana DUMITRAŞCU

Department of Management, Marketing and Business Administration

Faculty of Economics,

Sibiu, Romania

\title{
TOTAL PERFORMANCE SCORECARD
}

\author{
Keywords \\ Balanced scorecard \\ Total performance scorecard \\ Human resource
}

JEL classification

M12

\begin{abstract}
The purpose of this paper is to present the evolution of the Balanced Scorecard from a measurement instrument to a strategic performance management tool and to highlight the advantages of implementing the Total Performance Scorecard, especially for Human Resource Management. The study has been accomplished using the methodology of bibliographic study and various secondary sources.

Implementing the classical Balanced Scorecard indicated over the years, repeatedly failure. It can be indicated that the crucial level is determined by the learning and growth perspective. It has been developed from a human perspective, which focused on staff satisfaction, innovation perspective with focus on future developments.

Integrating the Total Performance Scorecard in an overall framework assures the company's success, by keeping track of the individual goals, the company's objectives and strategic directions. Like this, individual identity can be linked to corporate brand, individual aspirations to business goals and individual learning objectives to needed organizational capabilities.
\end{abstract}




\section{INTRODUCTION}

Lately, the question in every businessmen's mind is ,how to be successful under economic uncertainty and growing competition?". There are many possible answers to this question and most of them refer to finding or maintaining a competitive advantage by implementing one of the modern directions like quality management and performance management, in order to ensure that the company's goals are consistently being met in an effective and efficient manner.

The Balanced Scorecard represents a set of indicators that assures a unitary presentation of the management vision regarding the performance control and supposes the relational approach on four dimensions: financial perspective, customers' perspective, internal business processes and organizational learning and growth perspective.

No matter what an organization intents to do and what tools it uses, the crucial element which decides the failure or success of the action is the human resource. Every member of an organization affects its "learning" capacity. This is why, when creating a learning organization, it is important to align personal and organizational performance and reinforce one another on a sustainable base. Organizational scorecards need to be aligned with individuals' scorecards to turn the Balance Scorecard into a powerful tool for sustained organizational performance.

\section{BALANCED SCORECARD- FROM MEASUREMENT DASHBOARDS TO STRATEGIC PERFORMANCE MANAGEMENT FRAMEWORK}

To achieve success in the information era, companies need more than prudent investment in physical assets and excellent management of financial assets and liabilities. Companies mobilize and create value from their intangible assets as well as their physical and financial ones.

The Balanced Scorecard is the most well-known strategic performance management tool. The term was introduced by Robert S. Kaplan and David P. Norton in the article entitled "The Balanced Scorecard -- Measures that Drive Performance", appeared in the Jan/Feb 1992 issue of Harvard Business Review, figure 1.

The Balanced Scorecard (BSC) provides a system for measuring and managing all aspects of company's performance. The scorecard balances traditional financial measures of success, such as profits and return on capital, with non-financial measures of the drivers of future financial performance. The Balanced Scorecard measures organizational performance across different perspectives.

The Balanced Scorecard was created as an approach to measurement and was initially designed as a semi-standard structured report, supported by a series of design methods and automation tools. After noticing the manager's tendency of relying mostly on financial accounting measures, Kaplan and Norton established their tool as a scorecard that took also other measures into account, including process measures and customer satisfaction. They proposed a matrix with four types of measures: Financial Measures, Internal Business Measures, Innovation and Learning Measures, and Customer Measures. 


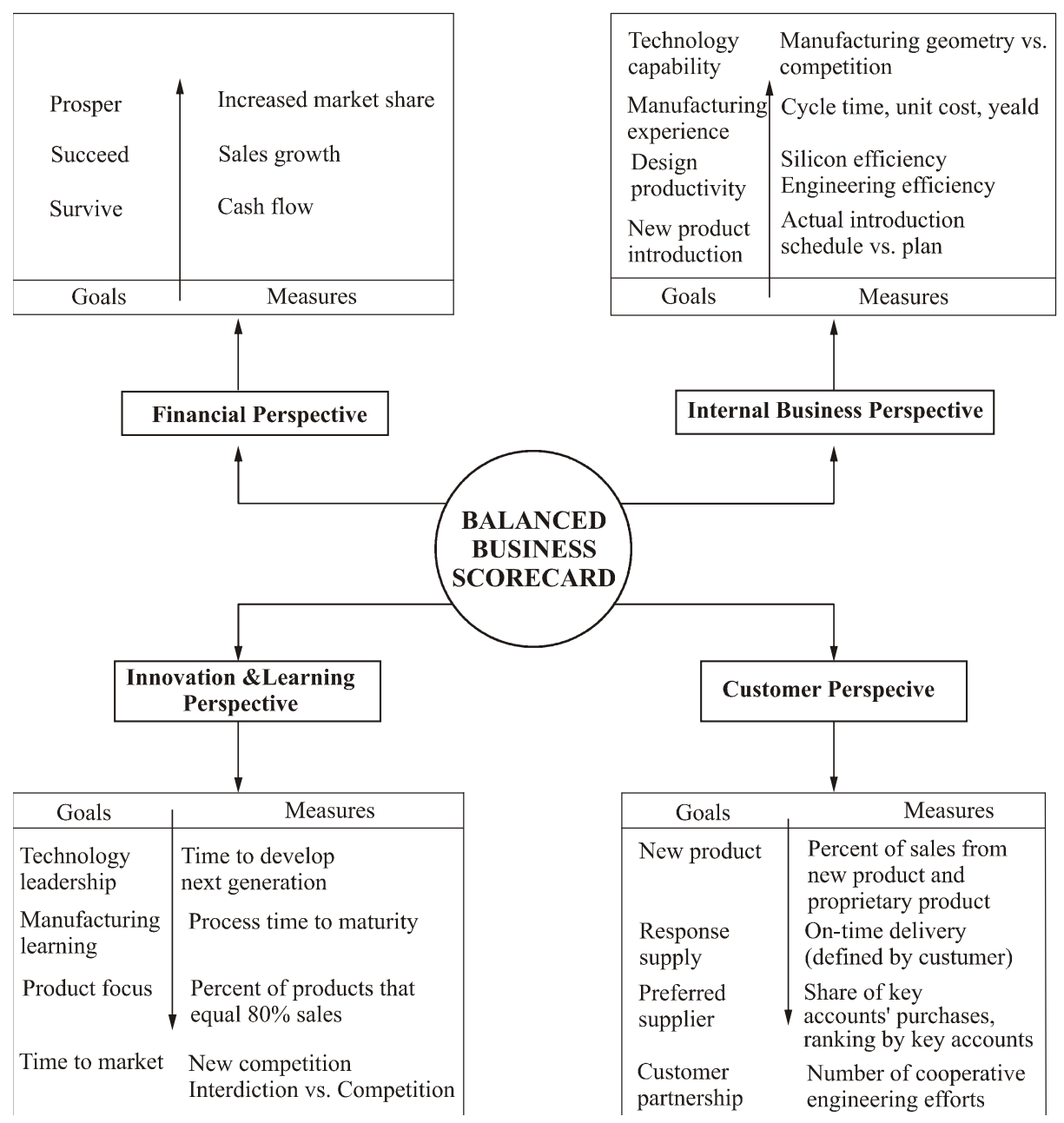

Figure 1. Balanced Business Scorecard - source [2]

Initially, the Balanced Scorecard focused on how managers could identify the best measures in each of the four areas as shown in figure no.1, but very soon the two realized the importance of linking the four categories of measures used to determine if the goals are being met with the company's strategy and its goals as proposed in the article "Putting the Balanced Scorecard to Work." from Sept/Oct 1993. Figure no.3 provides an overview of the approach they proposed.

The Balanced Scorecard identifies the Strategic Objectives and prioritizes the most important business issues in a long and short perspective and sets up performance criteria, actions or process progresses in order to meet the objectives. It is a way of integrating Business Strategy, Profiling, and Business Planning for Action.
The BSC is orientated in the whole company in order to:

- Clarify the company strategy, vision and strategy goals by taking into consideration the employees

- To build a management team

- Communicate the new strategy

- Create the basics for strategic learning

- Match resources and strategic initiatives

- Sustain investments

The Financial Perspective usually dictates the company's activities for a long and a short term. For each financial target the initiatives through the other three perspectives must be tracked. For example for improving the return of sales following steps have to be done: 


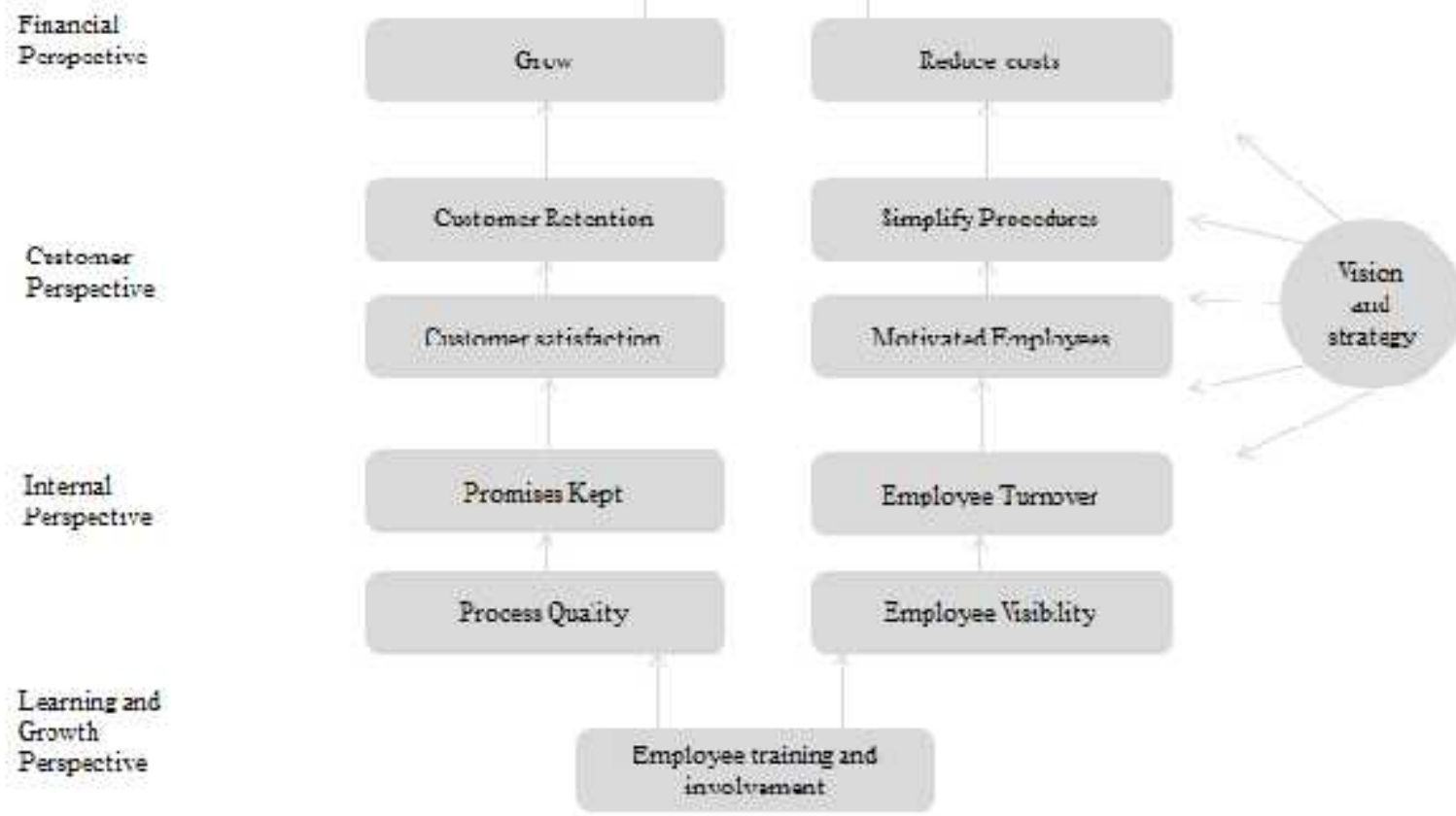

Figure 2. Return on sales tracked through the other three perspectives - source [6]

The next step in the Balanced Scorecard evolution is the 2000 Kaplan and Norton article "Having Trouble with Your Strategy? Then Map It". This strategy mapping is a tool that explicitly shows how value is created for the

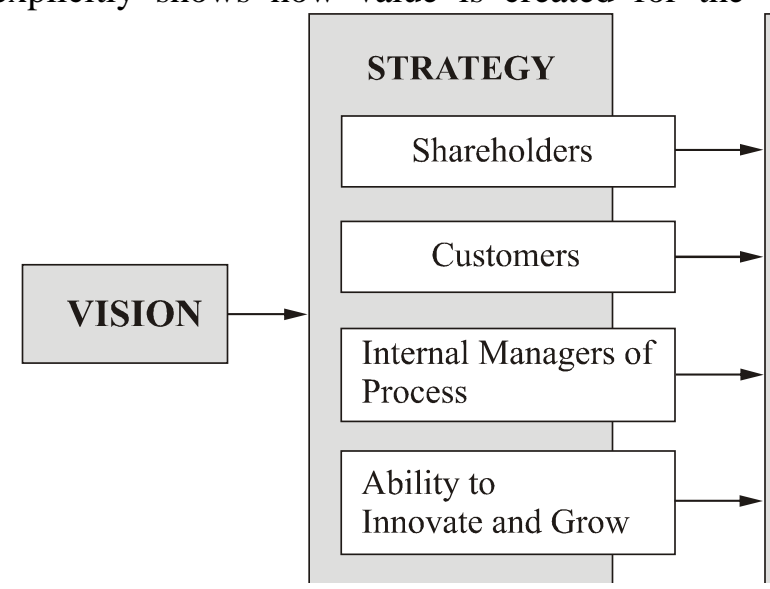

Figure 3. Linking strategies to Bala

Also, the design of the strategic map shows the cause-effect relationship between the elements. company, see figure no.3. The four box model is transformed in a strategic map which places the four perspectives in a mutual relation to show that the objectives support each other.

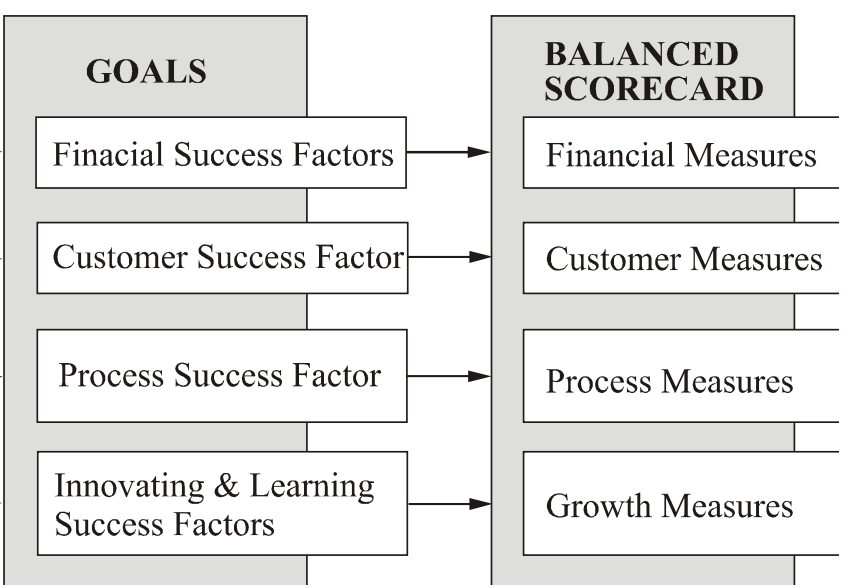

d Scorecard Measures- source [5]

Improving performance in the objectives found in the Learning and Growth perspective enables the organization to improve its Internal Process 
perspective objectives, which in turn enables the organization to create desirable results in the
Customer sector which finally leads to affect the Financial perspectives.

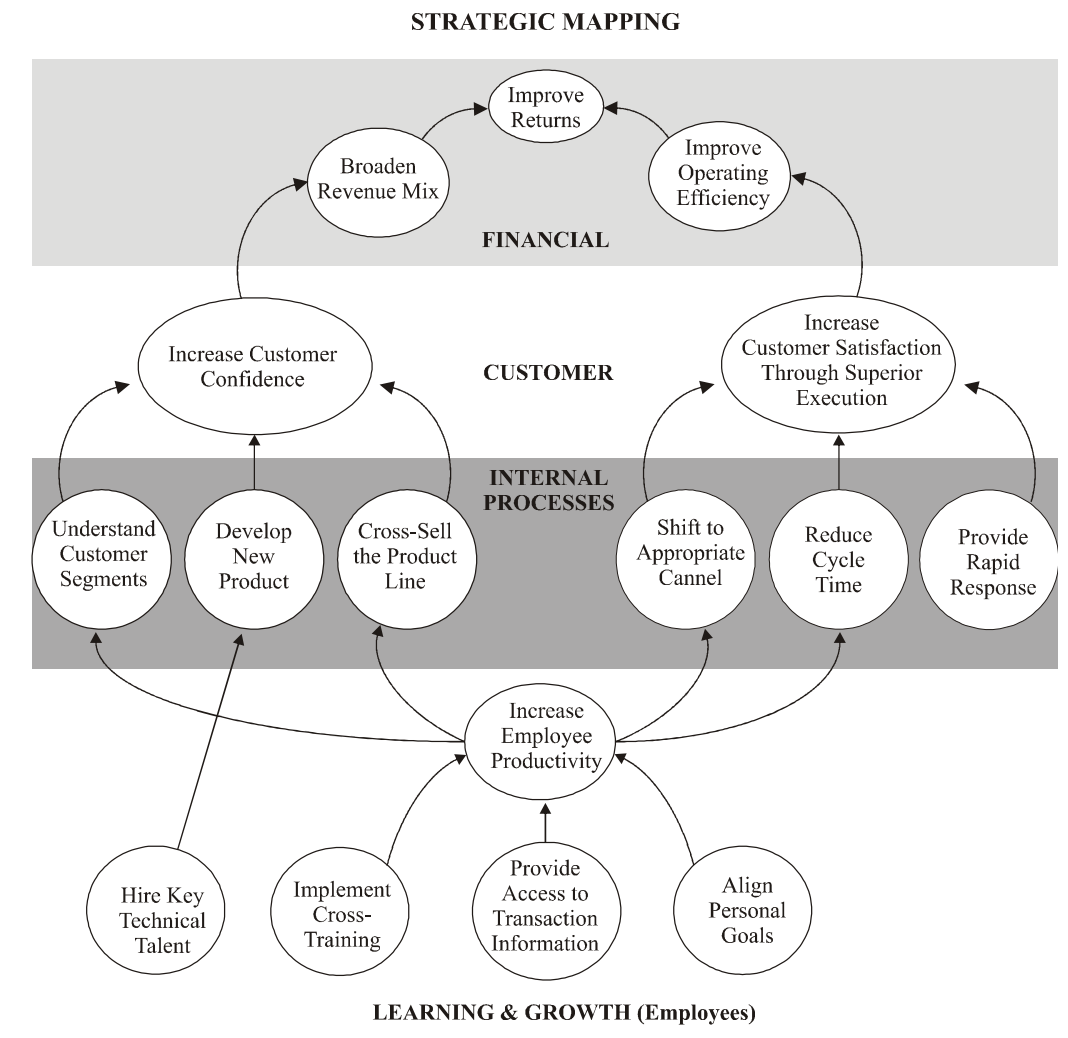

Figure 4. Balanced Scorecard Strategy Maps - source [4]

\section{TOTAL PERFORMANCE SCORECARD OR THE NEED OF A GOOD HR MANAGER}

Although the Balanced Scorecard was a popular tool (especially in the USA) even since its first mention, numerous case studies indicated that the implementation of this concept has been disappointing. Of course, there always are some difficulties when it comes to putting theory into practice, but a repeatedly failure of the implementation of the Balanced Scorecard must mean that there is a problem common to more companies. Theory looks good, so where is the problem? - If we look at the strategically mapping scheme, it is easy to determine that the crucial level is the one at the base of the system, the one that refers to learning. Also, the Learning and Growth perspective is the one that suffered most changes in content over the years. It has been developed from Human perspective, which focused on staff satisfaction, to Innovation perspective with focus on future developments. In order to avoid confusion or the chase of missing out important keys for performance, Kaplan and Norton have pointed out the way they see the most appropriate Learning and Growth perspective by creating three subsections as in the following scheme:

Traditional business management concepts are insufficiently committed to learning and in consequence there are many superficial improvements, just temporary changes, which lack sufficient personnel involvement and can actually lead to adverse effect.

Organizations today desire from their employees abilities like creativity, rapid learning and productivity. These skills are possessed by many people, but that does not mean that employees will share those skills all the time, just on demand. Employees nowadays are preoccupied with their careers so they are interested in gaining skills from employment and increasing their own value in their field, meaning they want proper trainings, mentoring programs and 
development possibilities. It is getting harder for managers to convince the personnel to have a long term commitment towards an organization so leaders need to take into consideration new innovative tools in order to find out the best ways in which they can attract, train and maintain employees. Fortunately for managers, humans have a strong need for community, therefore managers can link individual identity to corporate brand, individual aspirations to business goals, and individual learning objectives to needed organizational capabilities. Such a holistic management concept is Total Performance Scorecard.

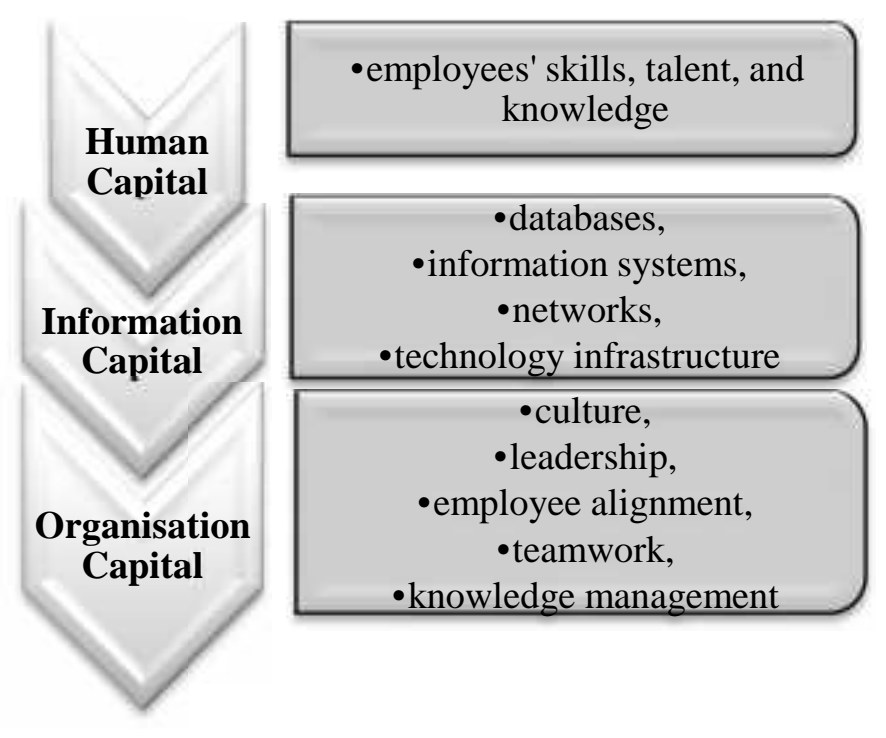

Figure 5. The Learning and Growth perspectives subsection

Source: after Kaplan, R.S. and D.P. Norton, 2000 


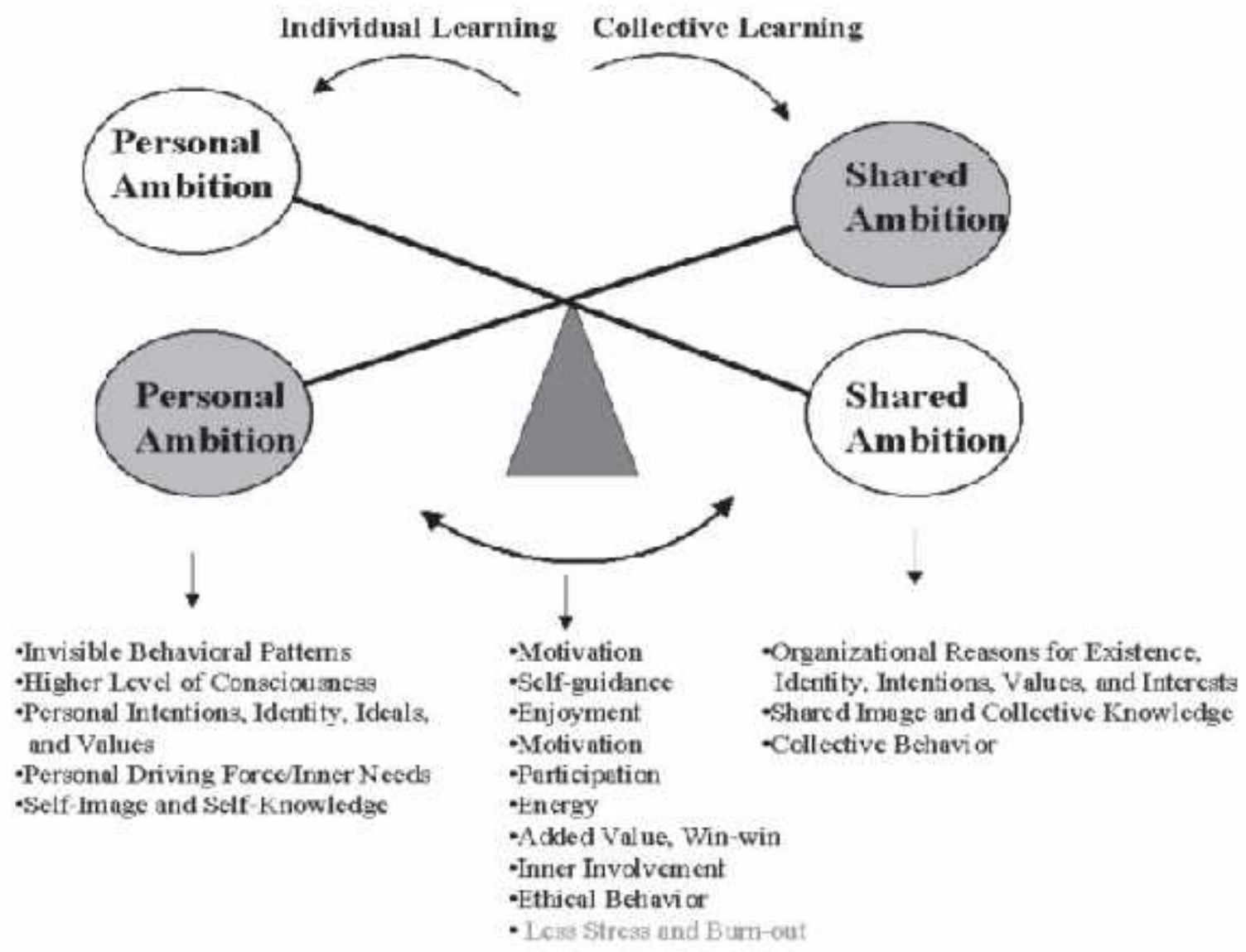

Figure 6. Aligning personal ambition to Shared Organizational Ambition - source [4]

Total Performance Scorecard is defined as the systematic process of continuous, gradual, and routine improvement, development and learning, focused on a sustainable increase of personal and organizational performances.

This framework tries to mark the common road of both individual goals and the company's goals, in order to obtain maximum satisfaction for both parts involved. The Total Performance Scorecard combines two separate balanced scorecards: the personal one (PBSC) and the organizational one (OBSC). Correlating the two of them is the perfect framework for improving the entire organization, as well as for the development of human potential.
The PBSC focuses on personal mission, vision, key roles, critical success factors, objectives, performance measures, targets, and improvement actions of the employee, while the OBSC focuses on the same factors but from the perspective of achieving competitive advantage for the company. 


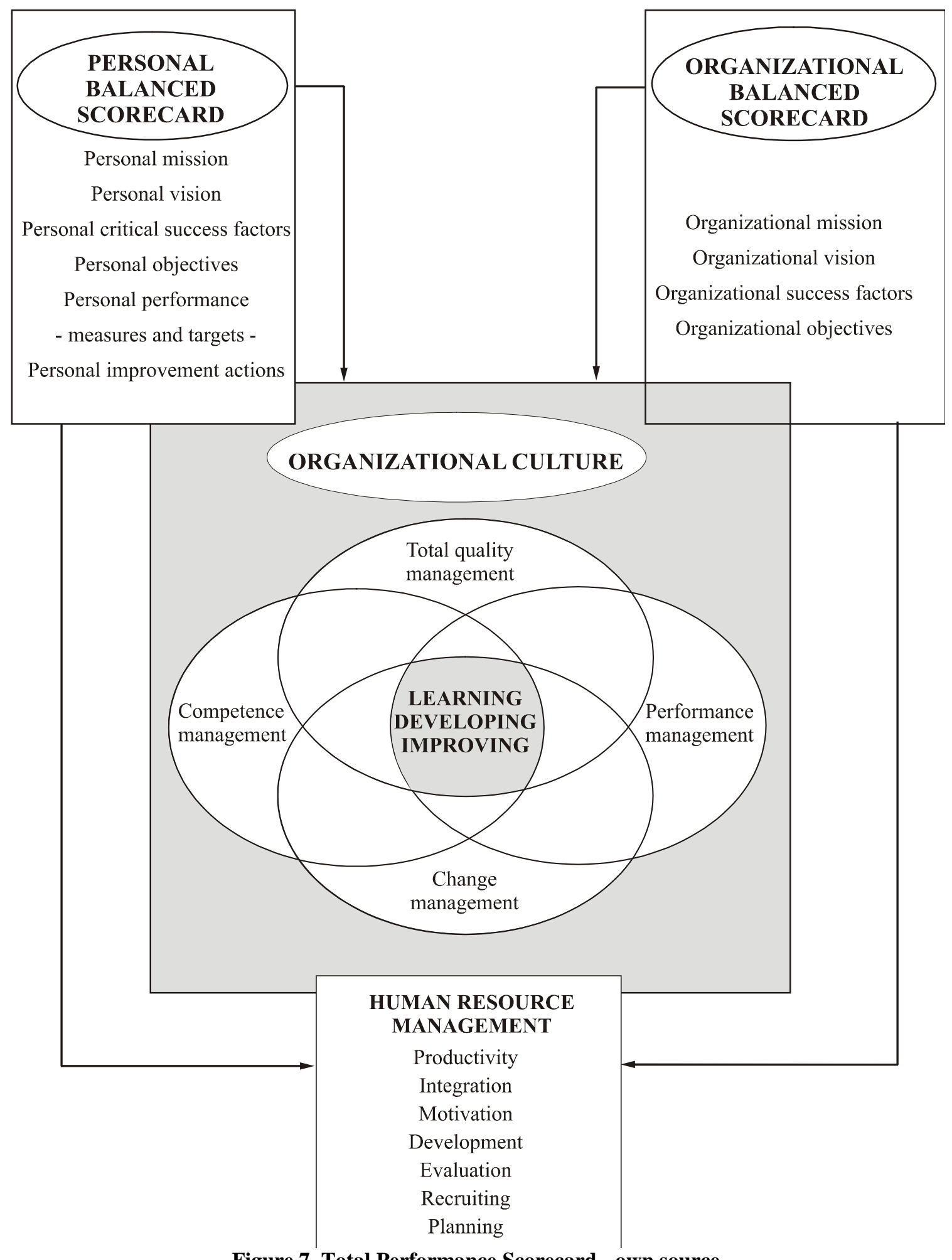

Figure 7. Total Performance Scorecard - own source

The result of combining PBSC with the OBSC is a strong organizational culture that represents both the organization and the individual, fact which makes the last to be more productive and indirectly the organization more successful.

At the base of this framework there is the Human Resource Department (HRD) which 
deals with management of people within the organization. HRD has a number of responsibilities, like planning, attracting employees, hiring members of staff, and another series of actions which are meant to make them perform to expectation.

Recruiting is one of the most fundamental roles of the HR department because this function ensures that the company selects the most adequate persons. This function involves evaluation of ability and competence of potential employees, in relation to what the company needs and this is why aligning the two balanced scorecards is extremely useful. The company should conduct educational and psychological measurements which involve assessment of abilities, skills and character evaluation of applicants. Trying to discover every level of the personal balanced scorecard of an individual, the human resource manager can assess if a candidate has the right abilities, attitude necessary to fit into the organization taking into consideration all long term common objectives of the company.

Motivation is the heart of managing people and one of the biggest responsibilities of the human resource department. The Personal Balanced Scorecard is extremely useful for managers because it gives information about the thing that could motivate employees. Even personal financial gain may not be enough of a motive. Research shows that individuals are motivated best by a combination of intrinsic motives (I enjoy doing this for some personal reason) and extrinsic ones (doing this gains me more recognition or more financial security). Therefore, leaders who can provide both intrinsic and extrinsic motives for their employees are more likely to retain them and their valuable knowledge.

The problems in this approach can sometimes be the fact that people are not always clear about their own objectives or the managerial lack of understanding of basic human behavior. This is why modern organizations need leaders who understand what motivates people, the best forms of interpersonal communication, and the human inclination to interpret human behavior. Managers who have a sophisticated understanding of human psychology and know how to use it in the workplace are more likely to have no problem when using Total Performance Scorecard and have an innovative employee base.

The HRD is also in charge of planning future organizational goals in relation to people or clarifying these same goals to staff members. This function of the department ensures that people in the organization have a general direction which they are working towards. Organizations that have a clear direction are always more effective; those members of staff will be more result oriented rather than just working for the sake of it.

The Total Performance Scorecard frame provides the solution to use the personnel's capabilities, driven by personal goals, in the most productive way in order to achieve the company's goals. This can be done by integrating concepts such as the Balanced Scorecard, Total Quality Management, Performance Management, Competence Management, and Change Management into one overall framework.

Competence Management is continuously delivering top performances with a motivated and developed community. It focuses on the maximum development of employees and makes optimal use of their potential in order to achieve the goals of the organization. It involves the development of job-related competences; a collection of information, capabilities, experience, skills, attitudes, standards, values, views, and principles (knowledge) that is focused on the expert fulfillment of the job.

The formulation of PBSC, respectively the personal mission and vision of the employee is meant to improve its learning ability and thus enable organizational learning to a collective change pattern, an organizational change.

Total quality management (TQM) comes as an integrated effort designed to improve quality performance at every level of the organization. TQM encompasses a disciplined way of life within the entire organization whereby continuous improvement of one's job and the organization stand central. Defining problems, determining root causes, taking actions, checking the effectiveness of these actions and reviewing business processes are done here in a routine, systematic and consistent way (Rampersad, 2004). Part of the TQM philosophy 
is the role of employees which are considered a vital element of the effort to achieve high quality. Their contributions are highly valued, and their suggestions are implemented. In order to perform this function, employees are given continual and extensive training, which needs to be correlated with the individual's actual need not just mistakenly equate learning with formal training sessions.

Effective talent management, career management and Human Resource Management in general need to take into consideration all of the information the Total Performance Scorecard provides because people do not work with devotion and do not spend energy on something they do not believe in or agree with. Clarity and uniformity of personal and organizational values and principles are, therefore, essential for the active involvement of people.

\section{CONCLUSIONS}

Nowadays it is getting harder to attract, train and maintain employees and to convince them to have a long term commitment towards the company.

Experience tells us that identification with the organization is the most important motive for employees to dedicate themselves actively to the organizational objectives. All people have different personal values and principles that an organization must try to understand in order to attract and maintain the most important resource it has, the employee.

Enjoyment at work, as a result of the balance between personal ambition and the shared ambition, employee involvement at work is stimulated and so more "warmth" within the organization is created. The result is enhancing happiness at work by reducing the gap between company life and normal life and between the way people deal with their colleagues at work and the way they act with their friends and family in their spare time, creating so a strong organizational culture.

Organizations whose leaders regard the development of people as one of the primary responsibilities of all managers have a competitive advantage because a person whose personal learning goals are aligned with those of the organization are likely to be fully engaged and highly productive. This also leads to loyalty and commitment not through patronizing but through providing an interesting and exciting place to work, perfect for enhancing creativity. Using a Total Performance Scorecard, integrated in an overall framework that keeps track of individual desires, company's objectives and principles of modern management directions means assuring the organization's success. This can be done by incorporating notions like Balances Scorecard, Total Quality Management, Performance Management, Competence Management and Change Management into one overall structure.

\section{References:}

[1] Angel, R. \& H.K. Rampersad, Do scorecards add up? CA-Magazine, Canada, May 2005.

[2] Kaplan and Norton's "The Balanced Scorecard Measures that Drive Performance." HBR Jan/Feb 1992.

[3] Kaplan, R.S. \& D.P. Norton, The Balanced Scorecard: translating strategy into action, Harvard Business School Press, Boston, 1996

[4] Kaplan, R.S. \& D.P. Norton, The Strategyfocused Organization: how balanced scorecard companies thrive in the new business environment, Harvard Business School Press, Boston, 2000

[5] Kaplan, R.S. \& D.P. Norton, "Having Trouble with Your Strategy? Then Map It" Harvard Business School Press, Boston, 2000

[6] Lauritzen, J. \& Krogager, E., Management accounting, financial measurement and planning, Volume 2, Nordisk Forlag A/S., Denmark, 2000

[7] Rampersad, H.K, The Personal Balanced Scorecard; The Way to Individual Happiness, Personal Integrity and Organizational Effectiveness, Tata McGraw-Hill, India, 2006

[8] Rampersad, H.K., Total Performance Scorecard; Redefining Management to Achieve Performance with Integrity, ButterworthHeinemann Business Books, Elsevier Science, Massachusetts, May 2003.

[9] Paul Harmon- The evolution of the Balanced Scorecard, Business Process Trends, May 2003

[10] http://pbuniversity.wordpress.com/2010/06/06/f oreword-total-performance-scorecard-byharvard-business-school-professor-dorothy-aleonard/

[11] http://www.humancapitalreview.org/content/def ault.asp?Article_ID $=710 \&$ ArticlePage_ID $=1460$ \&cntPage $=2$ 